\title{
PENGEMBANGAN LEMBAR KERJA PESERTA DIDIK BERDASARKAN STUDI KEANEKARAGAMAN JAMUR MARKOSKOPIS DI TANDAN KOSONG KELAPA SAWIT
}

\author{
Linda Gustia ${ }^{1 *}$, Ariefa Primair Yani $^{1}$, Sri Irawati ${ }^{1}$ \\ ${ }^{1}$ Program Studi Pendidikan Biologi Fakultas Keguruan dan Ilmu Pendidikan, Universitas Bengkulu \\ Email: lindasone15@gmail.com
}

\begin{abstract}
Abstrak
Penelitian ini bertujuan untuk mengetahui kelayakan Lembar Kerja Peserta Didik (LKPD) berdasarkan studi keanekaragaman jamur makroskopis di tandan kosong kelapa sawit PT Sandabi Indah Lestari. Subjek penelitian ini adalah peserta didik kelas X IPA 1 Sekolah Menengah Atas Negeri 08 Bengkulu Utara sementara objek penelitian ini adalah LKPD. Teknik pengumpulan data pada penelitian ini adalah observasi dan angket. Instrumen yang digunakan lembar angket untuk empat orang validator (dua orang Dosen Pendidikan Biologi dan dua guru Biologi), dan lembar tes untuk peserta didik. Analisis data validasi logis LKPD menggunakan skala likert. Teknik analisis data validasi empiris LKPD dengan menilai soal tes yang ada di LKPD yang telah dikerjakan kepada peserta didik. Nilai tersebut dirata-ratakan kemudian disesuaikan dengan kategori penilaian. Berdasarkan hasill validasi logis yang telah dilakukan, LKPD yang disusun memperoleh total persentase $81 \%$ dengan kategori sangat valid. Hasil validasi empiris oleh peserta didik memperoleh nilai rata-rata $78,66 \%$ dengan kategori baik. Berdasarkan hasil validasi logis dan validasi empiris tersebut, LKPD yang dikembangkan ini dinyatakan layak digunakan sebagai bahan ajar oleh peserta didik kelas $X$ pada materi fungi.

Kata kunci: Jamur Makroskopis, Lembar Kerja Peserta Didik (LKPD), Tandan Kosong Kelapa Sawit
\end{abstract}

\begin{abstract}
This study aims to determine the feasibility of student worksheets based on studies of macroscopic fungal diversity in empty oil palm bunches of PT Sandabi Indah Lestari. The subjects of this study were students of class X IPA 1 State Senior High School 08 Bengkulu Utara, while the object of this study was LKPD. Data collection techniques in this study were observation and questionnaires. The instrument used was a questionnaire sheet for four validators (two Biology Education lecturers and two Biology teachers), and a test sheet for students. The logical validation data analysis of LKPD used a Likert scale. The technique of analyzing data is the empirical validation of LKPD by assessing the test questions that are in the LKPD that have been done to students. The value is averaged and then adjusted to the assessment category. Based on the results of the logical validation that had been done, the LKPD that was compiled obtained a total percentage of $81 \%$ with the very valid category. The results of empirical validation by students obtained an average value of $78.66 \%$ with a good category. Based on the results of the logical validation and empirical validation, the developed LKPD was declared suitable for use as teaching material by class $\mathrm{X}$ students on fungi material.
\end{abstract}

Keyword: Macroscopic fungi, Student Worksheets, Oil Palm Empty Bunches

\section{PENDAHULUAN}

Indonesia memiliki luas kawasan 1,905 juta $\mathrm{km}^{2}, 13.466$ pulau dan iklim yang tropis (Darajati, 2016). Hal itulah yang menjadikan Indonesia memiliki tingkat keanekaragaman spesies yang tinggi, termasuk kingdom fungi. Terdapat 750.000 jenis fungi yang sudah dideskripsikan di dunia dan 80.000 diantaranya terdapat di Indonesia (Darajati, 2016).

Jamur adalah organisme eukariotik yang memiliki dinding sel dan heterotrof (Anggraeny, 2013). Jadi, untuk keberlangsungan hidupnya, jamur 
mendapatkan nutrisi dengan cara penyerapan nutrisi dari mahluk hidup lainnya. Jamur biasanya banyak ditemukan di tempat yang lembab, sedikit asam, kurang cahaya matahari (Wahyuni, 2010) dan dapat ditemukan pada kayu lapuk, tanah, serta tandan kosong kelapa sawit (Qosyatun, 2018).

Tandan kosong kelapa sawit memiliki kandungan selulosa yang tinggi. Hal ini sesuai dengan penelitian Ali, dkk (2013) yang menyatakan bahwa tandan kosong kelapa sawit memiliki kandungan selulosa hingga $40 \%$. Kandungan selulosa pada tandan kosong kelapa sawit inilah yang dibutuhkan oleh jamur makroskopis sehingga cocok sebagai media tumbuh jamur makroskopis.

Keanekaragaman jamur makroskopis di tandan kosong kelapa sawit memiliki banyak manfaat. Selain dapat dikonsumsi, juga dapat dijadikan sumber belajar. Pemanfaatan jamur makroskopis menjadi sumber belajar dapat menciptakan pembelajaran yang bermakna. Winarni (2018) menyatakan bahwa belajar akan lebih bermakna jika peserta didik mengalami langsung apa yang dipelajarinya. Mata pelajaran biologi dapat membuat peserta didik mengalami langsung apa yang dipelajarinya karena mata pelajaran biologi memerlukan kegiatan praktikum.

Sesuai KD 4.7 pada materi biologi kelas $\mathrm{X}$, materi fungi sangat membutuhkan kegiatan praktikum untuk mengamati secara langsung keanekaragaman jamur makroskopis (Kurikukum 2013). Oleh karena itu, diperlukan keanekaragaman jamur makroskopis dari lingkungan sekitar dan Lembar Kerja Peserta Didik (LKPD) berbasis studi potensi lokal. LKPD berbasis studi potensi lokal akan lebih kontekstual dengan lingkungan sekitar peserta didik. LKPD yang kontekstual juga akan meningkatkan motivasi dan menarik peserta didik dalam belajar (Noor, 2014). Pendapat ini juga didukung oleh Abadi, dkk (2018) yang menyatakan bahwa LKPD berdasarkan studi potensi lokal sangat diminati oleh peserta didik.

Berdasarkan oberservasi di SMA Negeri 8 Bengkulu Utara diketahui bahwa LKPD yang digunakan belum efektif. Hal ini dikarenakan LKPD belum mampu menjalankan fungsinya dengan baik yaitu membantu mempermudah untuk mengarahkan kegiatan pembelajaran. LKPD tidak berdasarkan hasil studi potensi lokal sehingga materi yang dicantumkan tidak konstektual dengan apa yang ada di lingkungan sekitar. LKPD juga kurang memberikan pengalaman belajar dan kurang menarik.

Menyikapi masalah tersebut, tindakan yang dilakukan adalah menjadikan jamur makroskopis yang ada di lingkungan sekitar sebagai sumber belajar dalam bentuk LKPD. Pengembangan LKPD berdasarkan hasil studi ini diharapkan mampu meningkatkan keterlibatan peserta didik, memotivasi, dan menarik peserta didik untuk belajar. Serta diharapkan pula peserta didik dapat mengalami pembelajaran yang bermakna.

\section{METODE}

Jenis penelitian yang dilakukan adalah penelitian pengembangan. Prosedur penelitian yang dilakukan mengadaptasi dari Sugiyono (2012). Adapun langkah-langkah prosedur penelitian ini yaitu: 1). Potensi dan masalah; 2). Pengumpulan data; 3). Desain produk; 4). Validasi desain (Validasi logis LKPD); 5). Revisi desain; dan 6). Validasi empiris LKPD.

Penelitian ini telah dilaksanakan pada awal bulan April 2019 di SMA Negeri 08 Bengkulu Utara. Subjek penelitian ini adalah peserta didik kelas X IPA 1 yang berjumlah 
27. Objek penelitian ini adalah LKPD. Variabel penelitian ini adalah LKPD hasil pengembangan dari studi keanekaragaman jamur makroskopis di tandan kosong kelapa sawit. Teknik pengumpulan data untuk validasi logis LKPD dalam penelitian ini adalah angket yang dimodifikasi dari penelitian Fajri (2018). Sedangkan teknik pengumpulan data untuk validasi empiris LKPD dalam penelitian ini adalah tes.

Teknik analisis data pada penelitian ini yang pertama yaitu analisis validasi logis LKPD. Data hasil validasi logis LKPD yang diperoleh dari masing-masing validator didapatkan dengan menggunakan skala likert. Skor dari masing-masing aspek akan dihitung menggunakan rumus berikut:

Jumlah Skor Lembar Validasi Skor Maksimal $x 100 \%$

(Riduwan, 2013).

Hasil persentase dari masing-masing aspek dihitung rata-ratanya, kemudian disesuaikan dengan kategori penilaian pada Tabel 1.

Tabel 1. Kategori Penilaian Kevalidan LKPD

\begin{tabular}{cc}
\hline Persentase & Kategori \\
\hline $81 \%-100 \%$ & Sangat valid \\
$61 \%-80 \%$ & Valid \\
$41 \%-60 \%$ & Cukup Valid \\
$21 \%-40 \%$ & Kurang Valid \\
$0 \%-20 \%$ & Tidak Valid \\
\hline & (Riduwan, 2013).
\end{tabular}

Jika persentase mencapai $61 \%$ atau lebih, maka produk pengembangan LKPD dinyatakan layak untuk digunakan.

Teknik analisis data yang kedua yaitu validasi empiris LKPD dengan memberikan soal tes yang ada di LKPD kepada peserta didik. Soal tes yang telah dikerjakan oleh masing-masing peserta didik dinilai. Nilai tersebut dirata-ratakan dan disesuaikan dengan kategori penilaian pada Tabel 2 .

Tabel 2. Kategori penilaian soal tes di LKPD

\begin{tabular}{cc}
\hline Persentase & Kategori \\
\hline $81-100$ & Sangat Baik \\
$61-80$ & Baik \\
$41-60$ & Cukup Baik \\
$21-40$ & Kurang Baik \\
$0-20$ & Tidak Baik \\
\hline & (Riduwan, 2013).
\end{tabular}

Jika nilai rata-rata mencapai 61 atau lebih, maka produk pengembangan LKPD dinyatakan layak untuk digunakan.

\section{HASIL DAN PEMBAHASAN}

LKPD yang telah disusun divalidasi logis oleh 4 orang validator yaitu 2 dosen Pendidikan Biologi dan 2 guru Biologi SMA. LKPD ini memperoleh rata-rata hasil persentase yang dapat dilihat pada Tabel 3.

Tabel 3. Persentase Validasi Logis LKPD oleh

\begin{tabular}{|c|c|c|c|}
\hline No. & $\begin{array}{c}\text { Aspek } \\
\text { Penilaian }\end{array}$ & Persentase & Kategori \\
\hline 1. & Isi/Materi & $80 \%$ & Valid \\
\hline 2. & Penyajian & $75 \%$ & Valid \\
\hline 3. & Kegrafikan & $87 \%$ & $\begin{array}{l}\text { Sangat } \\
\text { Valid }\end{array}$ \\
\hline & $\begin{array}{l}\text { ata-rata } \\
\text { rsentase }\end{array}$ & $81 \%$ & $\begin{array}{l}\text { Sangat } \\
\text { Valid }\end{array}$ \\
\hline
\end{tabular}

Aspek isi/materi memperoleh persentase $80 \%$ dengan kategori valid. Pada aspek penyajian memperoleh persentase hanya $75 \%$. Hal ini dikarenakan LKPD awal penyusunannya kurang sistematis. Selain dari penyusunan, terdapat beberapa soal yang tidak menguatkan pemahaman konsep. Pada aspek kegrafikan, LKPD ini memperoleh persentase $87 \%$ dengan kategori sangat valid. Hal ini dikarenakan desain LKPD awal 
dari bagian sampul hingga isi sudah dinilai baik. Untuk keseluruhan, LKPD hasil pengembangan ini dinyatakan layak karena memperoleh kategori sangat valid dengan persentase $81 \%$.

Meskipun LKPD ini dinyatakan valid, LKPD ini tetap mendapatkan beberapa saran dari para validator. Pada aspek isi/materi, terdapat 5 saran dari 3 validator. Ke-5 saran tersebut yaitu: 1). Sesuaikan materi dengan tingkat pendidikan; 2). Soal pada LKPD sesuaikan dengan tujuan kegiatan; 3). Lengkapi LKPD dengan hal-hal eksplorasi jamur; 4). Perbaiki cara kerja agar mudah dimengerti; 5). Lengkapi materi pada LKPD. Banyaknya saran menjadikan hasil validasi LKPD pada aspek isi/materi ini hanya memperoleh rata-rata persentase $80 \%$ dengan kategori valid. Aspek penyajian mendapat saran yaitu sistematika penyusunan LKPD sesuaikan dengan format LKPD. Pada aspek kegrafikan, terdapat 4 saran dari 3 validator. Ke-4 saran tersebut yaitu: 1). Perbaiki latar belakang dari LKPD. 2); Perbaiki jenis font; 3). Sertakan petunjuk gambar; 4). Sertakan foto jamur di tandan kosong kelapa sawit pada bagian cover LKPD. Meskipun mendapatkan 4 saran, LKPD ini tetap dinyatakan sangat valid dengan ratarata persentase $87 \%$. Sehingga secara keseluruhan, hasill validasi LKPD yang disusun memperoleh total persentase $81 \%$ dengan kategori sangat valid.

LKPD yang disusun juga disesuaikan dengan syarat teknis penyusunan LKPD. Penyusunan LKPD juga mengikuti panduan penyusunan menurut para ahli (Widjajanti, 2008; Depdiknas, 2008). Menggunakan huruf tebal dan agak besar pada topik. Perbandingan besar huruf dan gambar serasi. Gambar dapat menyampaikan isi/pesan secara efektif. Penampilan yang menarik. Struktur LKPD. Penyusunan LKPD yakni: judul, kompetensi yang akan dicapai, informasi pendukung, tugas-tugas dan langkah-langkah kerja. Perbandingan LKPD sebelum dan setelah direvisi sesuai dengan saran dari validator dapat dilihat pada Tabel 4.

Tabel 4. Perbandingan LKPD Sebelum dan Sesudah Direvisi

\begin{tabular}{|c|c|c|c|}
\hline No. & Bagian & Sesudah & Keterangan \\
\hline 1. & Cover & $\begin{array}{l}\text { LKPD } \\
\text { Eflotogit }\end{array}$ & $\begin{array}{l}\text { Cover setelah direvisi terdapat } \\
\text { gambar tumpukan tandan kosong } \\
\text { kelapa sawit. hal tersebut } \\
\text { menunjukan jamur yang diperoleh } \\
\text { berasal dari tandan kosong kelapa } \\
\text { sawit. }\end{array}$ \\
\hline 3. & $\begin{array}{l}\text { Font, Latar Belakang, } \\
\text { dan penyusunan LKPD }\end{array}$ & & $\begin{array}{l}\text { Font yang digunakan juga diganti } \\
\text { agar lebih menarik. Kemudian latar } \\
\text { belakang pun diganti agar lebih } \\
\text { menarik. Penyusunan juga diubah } \\
\text { dengan meletakkan materi tidak } \\
\text { lagi di lampiran }\end{array}$ \\
\hline
\end{tabular}




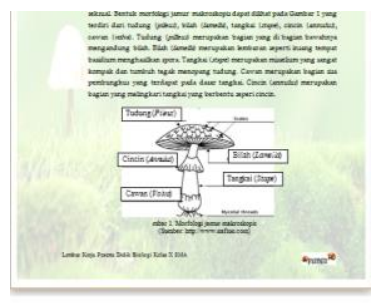

4. Materi dan Pertanyaan

LKPD yang telah divalidasi logis oleh validator, selanjutnya direvisi sesuai saran dari validator. Setelah direvisi, disusunlah desain akhir LKPD untuk divalidasi empiris oleh peserta didik. Uji validasi empiris ini dilakukan pada peserta didik kelas X IPA 1 SMA Negeri
Setelah direvisi, materi disesuaikan dengan tingkat pendidikan. Pertanyaan pada LKPD juga diganti dan disesuaikan dengan tujuan kegiatan LKPD.

Tabel 5. Hasil Penilaian Soal Tes di LKPD

\begin{tabular}{cccccc}
\hline Kelompok & \multicolumn{4}{c}{ Nilai } & \multicolumn{2}{c}{$\begin{array}{c}\text { Nilai } \\
\text { Akhir }\end{array}$} \\
\cline { 2 - 5 } & $\begin{array}{c}\text { Tabel } \\
\text { Pengamatan } \\
\text { (Skor Maks 10) }\end{array}$ & $\begin{array}{c}\text { Hasil } \\
\text { Pengamatan } \\
\text { (Skor Maks 10) }\end{array}$ & $\begin{array}{c}\text { Pertanyaan } \\
\text { (Skor Maks 60) }\end{array}$ & $\begin{array}{c}\text { Kesimpulan (Skor } \\
\text { Maks 20) }\end{array}$ \\
\cline { 2 - 5 } 1 & 7 & 8 & 45 & 15 & 75 \\
2 & 8 & 7 & 46 & 20 & 81 \\
3 & 9 & 9 & 53 & 15 & 86 \\
4 & 8 & 9 & 46 & 15 & 78 \\
5 & 7 & 8 & 39 & 10 & 64 \\
6 & 9 & 9 & 55 & 15 & 88 \\
& & Rata-rata & & & 78,66 \\
\hline
\end{tabular}

Hasil validasi empiris oleh peserta didik dinyatakan layak. Dinyatakan layak karena LKPD ini memperoleh nilai rata-rata $\geq 61$ yaitu $78,66 \%$ dengan kategori baik. Pada penelitian sebelumnya, Arningsih (2016) tentang validasi empiris LKPD pada materi fungi juga dinyatakan layak. Penilaian LKPD tersebut memperoleh nilai rata-rata sebesar 92,33 . Begitu juga pada penelitian Setiawati dkk. (2018) yang memperoleh nilai rata-rata 89,25 . Perbedaan nilai tersebut kemungkinan
08 Bengkulu Utara yang berjumlah 27 peserta didik. Uji validasi empiris ini dilakukan untuk menilai LKPD yang dikerjakan oleh peserta didik. Hasil penilaian LKPD dapat dilihat pada Tabel 5. 
Pengembangan LKPD berdasarkan hasil studi potensi lokal juga dapat meningkatkan hasil belajar. Hal ini sesuai dengan Zukmadini, dkk. (2018) yang menyatakan bahwa bahan ajar selain buku teks berdasarkan potensi lokal lebih efektif meningkatkan hasil belajar daripada buku teks. Kemudian Abadi, dkk (2018) juga menyatakan bahan ajar berdasarkan potensi lokal mampu meningkatkan kemampuan dan pengetahuan pesertas didik.

Berdasarkan uji validasi logis dan empiris, LKPD hasil pengembangan ini dinyatakan layak. Artinya LKPD layak sebagai bahan ajar pada materi fungi yang bisa digunakan oleh peserta didik. Materi biologi merupakan materi yang sangat berkaitan erat dengan lingkungan begitu juga dengan materi fungi. Materi fungi sangat membutuhkan kegiatan praktikum untuk pembuktian dan juga agar peserta didik dapat mengalami langsung apa yang dipelajarinya. Kegiatan praktikum ini didukung dengan penggunaan bahan ajar berupa LKPD yang kontekstual dengan lingkungan peserta didik. Dengan adanya LKPD materi fungi yang kontekstual ini, peserta didik akan lebih mudah dalam melakukan praktikum pada materi fungi.

\section{PENUTUP}

Simpulan

Berdasarkan hasil validasi logis dan empiris LKPD yang telah dilakukan, LKPD hasil pengembangan berdasarkan hasil studi keanekaragaman jamur makroskopis di tandan kosong kelapa sawit PT Sandabi Indah Lestari dinyatakan layak untuk dijadikan bahan dengan persentase $81 \%$ oleh validator dan nilai rata-rata 78,66 oleh peserta didik.

\section{Saran}

Sebaiknya ada penelitian lebih lanjut untuk menguji keefektifitasan LKPD hasil pengembangan berdasakan studi keanekaragaman jamur makroskopis di tandan kosong kelapa PT Sandabi Indah Lestari ini.

\section{DAFTAR PUSTAKA}

Abadi, M. K., Asih, E. C. M., \& Jupri, A. 2018. The development of interactive mathematics learning laterial based on local wisdom with. swf format. Journal of Physics: Conference Series. 4(2): 95104.

Ali, Nurhalieza, Amal, Fathie, Wan, dan Onn. 2013. Yield Performance and Biological Efficiency of Empty Fruit Bunch (EFB) and Palm Pressed Fibre (PPF) as Substrates for the Cultivation of Pleurotus Ostreatus. Jurnal Teknologi. 64(1): 93-99.

Anggraeny, Evy. 2013. Fungi (Jamur). https://anzdoc.com/fungi-jamur-bymsevy-anggraeny-sma-regina-pacis jakarta.html (diakses pada 10 September 2018).

Arningsih, Lenny. 2016. Pengembagan LKS Pada Pembelajaran Biologi Kelas $X$ Berdasarkan Hasil Studi Keanekaragaman Jamur Makroskopis di Limbah Padat Kelapa Sawit PT Bio Nusantara Teknologi Kabupaten Bengkulu Tengah. Skripsi. Tidak Diterbitkan. Program Studi Pendidikan Biologi Fakultas Keguruan dan IImu Pendidikan. Universitas Bengkulu: Bengkulu.

Darajati, Wahyuningsih. 2016. Indonesia Biodiversity Strategy and Action Plan. 
Jakarta: Kementrian Perencanaan Pemabangunan Nasional.

Depdiknas. 2008. Panduan Pengembangan Bahan Ajar. Jakarta: Direktorat Pembinaan Sekolah Menengah Atas.

Fadhilah, Hafiza dan Budiyanto. Pengaruh Tandan Kosong Kelapa Sawit sebagai Media Tumbuh Jamur terhadap Produksi dan Sifat Fisik Jamur Merang (Volvariella volvacea). Jurnal Agroindustri. 8(1): 80-96.

Fajri, Aziza., Abdul Rahman., dan Ariefa P. Yani. 2018. Pengembangan Lembar Kerja Peserta Didik Materi Vertebrata Kelas X Berdasarkan Inventarisasi Ikan Laut. Jurnal pendidikan dan pembelajaran biologi. 2(2): 52-57.

Hidayati, Mohammad, dan Asmawit. 2015. Pemanfaatan Serat Tandan Kosong Kelapa Sawit sebagai Media Pertumbuhan Jamur Tiram Putih. Jurnal Biopropal Industri. 6(2): 73-80.

Noor, Rasuane. 2014. Penyusunan Lembar Kerja Peserta Didik (LKPD) Biologi SMA Melalui Inventarisasi Tumbuhan yang Berpotensi atau Sebagai Pewarna Alami di Kota Metro. Jurnal Pendidikan Biologi Universitas Muhammadiyah Metro. 5(2): 94-104.

Qosyatun, Umi. 2019. Identifikasi Jamur Makroskopis Pada Limbah Sawit Di Perkebunan Kelapa Sawit Pt Hindoli
Kecamatan Sungai Lilin Dan Sumbangsihnya Pada Materi Jamur/Fungi Di Sma Kelas X. Diploma Thesis. Tidak diterbitkan. Uin Raden Fatah Palembang.

Riduwan. 2013. Skala Pengukuran VariabelVariabel Penelitian. Bandung: Alfabeta

Setiawati, Nindya Puri., Bhakti Karyadi., Ariefa P. Yani. 2018. Pengembangan Lkpd Ipa Berbasis Service Learning Untuk Meningkatkan Kemampuan Reflective Thinking Siswa. Jurnal Pendidikan dan Pembelajaran Biologi. 2(1): 76-85.

Wahyuni, Dwi. 2010. Mikologi Dasar. Jember: Jember University Press.

Widjajanti, Endang. 2013. Kualitas Lembar Kerja Peserta didik. Jurusan Pendidikan Kimia Fakultas Matematika dan IImu Pengetahuan Alam Universitas Yogyakarta.

Winarni, Endang Widi. 2018. Pendekatan IImiah dalam Pembelajaran Inovatif dan Kreatif. Bengkulu: Unit Penerbitan FKIP UNIB.

Zukmadini, Alif Yanuar., Dewi Jumiarni., dan Kasrina. $2018 . \quad$ Developing Antimicrobial Medicinal Plants Pocketbook Based On Local Wisdom Of Muko-Muko And Serawai Ethnics. Jurnal Pendidikan Biologi Indonesia. 4(2): 95-104. 